\title{
Recorregut de recerca geològica i mineralògica per la comarca del Matarranya: des de Beseit a Vall - de - Roures
}

Josep Maria Mata-Perelló

Andrés Pocoví Juan

Joaquim Sanz Balagué

Jaume Vilaltella

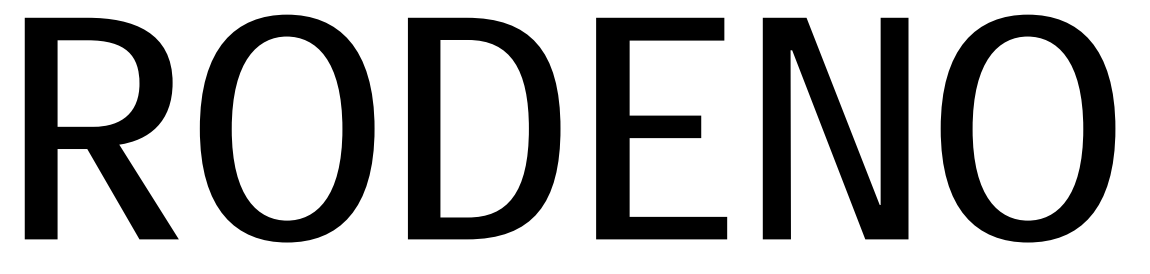

\section{REVISTA DE GEOLOGÍA ARAGONESA}

\section{n. 3}

SEPTIEMBRE 2015 


\section{RECORREGUT DE RECERCA GEOLÒGICA I MINERALÒGICA PER LA COMARCA DEL MATARRANYA: DES DE BESEIT A VALL - DE - ROURES}

\section{Josep Maria Mata-Perelló}

Museu de geologia Valentí Masachs, Escola Politècnica Superior d'Enginyeria de Manresa (EPSEM), Universitat Politècnica de Catalunya - BarcelonaTech (UPC), 08272 Manresa, Spain

\section{Andrés Pocovi Juan}

Universidad de Zaragoza, Departamento de Ciencias de la Tierra ( DCT- UZ)

\section{Joaquim Sanz Balagué}

Departament d'Enginyeria Minera i Recursos Naturals (EMRN), Escola Politècnica Superior d'Enginyeria de Manresa (EPSEM), Universitat Politècnica de Catalunya - BarcelonaTech (UPC), 08272 Manresa, Spain

\section{Jaume Vilaltella Farràs.}

Sociedad Española para la Defensa del Patrimonio Geológico y Minero (SEDPGYM)

\section{Palabras clave: patrimonio minero; patrimonio geológico}

\section{Resum}

Recorregut realitzat el 16 de novembre de 2013. En aquesta ocasió, el recorregut del present itinerari discorrerà per una zona en la qual conflueixen tres unitats geològiques netament diferenciades: la Depressió Geològica de I'Ebre, la Serralada Prelitoral Catalana (del Sistema Mediterrani), i la Serralada Ibèrica.

Així, cap els voltants de Beseit ho farà per la tercera unitat, a la denominada Zona d'Enllaç, prop ja del Sistema Ibèric. Cal dir que circularem més lluny de la zona corresponent a la segona unitat (la Serralada Prelitoral Catalana del Sistema Mediterrani).

Per d'altra banda, en diferents trams del recorregut, circularem per la primera titat (la Depressió Geològica de l'Ebre).

També cal dir d'altra banda, que el recorregut de l'itinerari discorrerà per una sola comarca, la del Matarranya, situant-se sempre dintre de la Regió de Tortosa. 


\section{ADVERTIMENTS PREVIS}

Com en altres recorreguts de RECERCA GEOLÒGICA I MINERALÒGICA ..., si es disposa del temps suficient, poden efectuar-se passant per totes les parades i filloles. En cas contrari, recomanem prescindir de les anomenades PARADES - CONDICIONALS.

També recomanem de cercar la informació més adient, sobre els trams a recórrer mitjançant camins de terra, o de pista. Precisament, en aquest itinerari, hi ha alguns trajectes d'aproximació cap a les mines, que haurem de fer per camins de terra en irregular estat de conservació.

Per d'altra banda, recomanem tenir una cura extrema de la NATURA, evitant qualsevol forma d'agressió sobre ella, o de fer-n’hi un mal ús del que en ofereix la nostra mare Terra.

\section{OBJECTIUS FONAMENTALS D’AQUEST ITINERARI}

Els objectius fonamentals que es pretenen aconseguir en aquest itinerari, es poden concretar en els següents aspectes generals:

1.- Observació i descripció dels materials terciaris (de l’Eocè i de l’Oligocè) de la Depressió Geològica de l'Ebre, que pertanyen majoritàriament al complex al-luvial de Gandesa - Horta de Sant Joan, que inclou, entre altres a la Formació Montsant i a la Formació Flix. Aquests materials, els anirem trobant a diferents indrets del recorregut de l'itinerari, pels termes de Beseit i de Vall-de-roures. Cal dir que bona part d'aquesta zona, s'inclou dintre del denominat Avant-país, situat al contacte entre la Depressió Geològica de l’Ebre i la Serralada Ibèrica.

2.- Observació i descripció dels materials mesozoics (del Triàsic, del Juràssic i del Cretàcic) i dels cenozoics (de l'Eocè i de l'Oligocè), que constitueixen la Serralada Prelitoral Catalana,. Aquests materials els trobarem a diferents indrets del recorregut de l'itinerari.

3.- Observació de les estructures locals d'aquestes unitats geològiques acabades d'esmentar, que trobarem al llarg del recorregut de l'itinerari, i de les relacions existents entre elles. Així:

3A) de l'estructura de Branca Externa de la Serralada Prelitoral Catalana (integrant del Sistema Mediterrani), que trobarem a diferents trams del recorregut. En molts indrets, aquests es troben prop de la seva Zona d'Enllaç amb el Sistema Ibèric.

3B) de l'estructura de la Depressió Geològica de l’Ebre, que veurem als darrers trams del recorregut.

3C) de les relacions existents entre les unitats i sotsunitats geològiques acabades d'esmentar. 
4.- Observació i reconeixement de diferents mineralitzacions situades a diferents indrets del recorregut de l'itinerari, (però sempre dintre de les dues branques de la Serralada Prelitoral Catalana), com són les formacions i explotacions lutítiques, situades fonamentalment a Beseit, dintre de la comarca del Matarranya, dintre de l'Albià (Cretàcic Inferior).

5.- Observació de les antigues explotacions mineres relacionades amb les mineralitzacions anteriors. Al respecte, cal dir que totes elles es troben actualment aturades. En aquest cas, cal fer esment de les explotacions de roques carbonatades, emprades per a la construcció de la Presa de l'Embassament de la Pena.

6.- Observació i anàlisi dels impactes produïts sobre el Medi Natural (i sobre el Medi Ambient), tant per les explotacions mineres anteriors, com per altres activitats humanes.

7.- Observació dels diferents indrets relacionats amb el Patrimoni Geològic i Miner, que trobarem al llarg del recorregut.

\section{ANTECEDENTS BIBLIOGRÀFICS}

Pel que fa al recorregut del present itinerari, existeixen alguns antecedents molt propers, obra del mateix autor del present itinerari. Es tracta de MATA-PERELLÓ (1996b, 1997, 2000a, 2000b, 2001a, 2001b i 2011). Un altre antecedent parcial, obra del mateix autor, es troba a MATA-PERELLÓ (1989), i correspon a un altre itinerari.

Pel que fa a la descripció de les mineralitzacions d'aquesta comarca, farem esment d'un altre treball del mateix autor, de MATA-PERELLÓ (1991), relatiu a les mineralitzacions catalanes en general. Uns altres antecedents, cal situar-los en MATAPERELLÓ (1995a, 1995b, 2005a y 2005b), relatius als inventaris mineralògics de les comarques de la Terra Alta i del Matarranya.

I, finalment, pel que fa a l'estructura geològica de la zona per la qual discorre l'itinerari, farem esment dels treballs de GUIMERÀ et altri (1982) i de RIBA et altri (1976). També, i dintre d'aquest apartat, també farem esment de diversos treballs de l'IGME (1972). Tots ells són relatius a diversos fulls geològics corresponents als indrets per on passarà el recorregut de l'itinerari.

Tots aquests treballs referenciats, i d'altres, figuren esmentats per ordre alfabètic a l'apartat dedicat a la BIBLIOGRAFIA. 


\section{RECORREGUT DE L'ITINERARI}

El recorregut de l'itinerari començarà al poble de Beseit, per on es farà una aturada. Després, el recorregut es dirigirà cap a la veïna població de Vall - de - Roures, passant abans per l’Embassament de la Pena.

En arribar a la segona població esmentada, finalitzarà el recorregut del present itinerari, dintre de la Depressió Geològica de l’Ebre.

\section{DESCRIPCIÓ DE L'ITINERARI}

Com de costum, estructurarem el recorregut de l'itinerari en una sèrie de PARADES, que tot seguit anirem veient. En cada una d'aquestes aturades farem un breu comentari (geològic o mineralògic, segons s'escaigui). Cada una d'aquestes parades tindrà un número, i un topònim representatiu. Per d'altra banda, śindicarà el nom del poble més proper, el municipi al qual pertany l'indret, i la comarca on es troba situat. Per d'altra banda, també indicarem en cada cas, i entre parèntesi, el full topogràfic on es troba l'aturada. Finalment, cal dir que el recorregut de l'itinerari s'inclourà dintre dels següents fulls, del "Mapa Topográfico Nacional", realitzats a l'escala 1:50.000 per l'Instituto Geográfico y Catastral": 496 (dit d'Horta de Sant Joan), 520 (dit de Pena-roja de Tastavins) i 521 (dit de Beseit.).

Així doncs, la relació de parades ordenades, que composen aquest itinerari geològic i mineralògic, és el següent:

\section{PARADA 1. PEDRERA I MINA D'ARGILA "MARIA DOLORS", (terme municipal de Beseit, comarca del Matarranya). (Full 521).}

Aquest recorregut, el podem iniciar en aquest indret, situat ben prop de Beseit /a menys de 1'5), poc abans d'entrar-hi, venint des de Vall-de-roures, la capital de la comarca, on ara ens trobem situats

En aquest indret, es troba una explotació dels nivells lutítics cretàcics, que pertanyen a l'Albià, i més concretament a la Formació Utrillas. Entre les argiles, el mineral més abundant és la CAOLINITA. Per d'altra banda, hi ha una notable presència dels òxids de ferro, especialment de l'HEMATITES (normalment terròs) i de la GOETHITA (la qual es presenta terrosa, en forma de LIMONITA).

Darrerament, aquests nivells argilosos han estat explotats per mineria a "cel obert" (o a "tall obert", com es diu a la zona). Tot i així, les primeres explotacions es van efectuar per mineria soterrània. FOTOGRAFIA 1. 


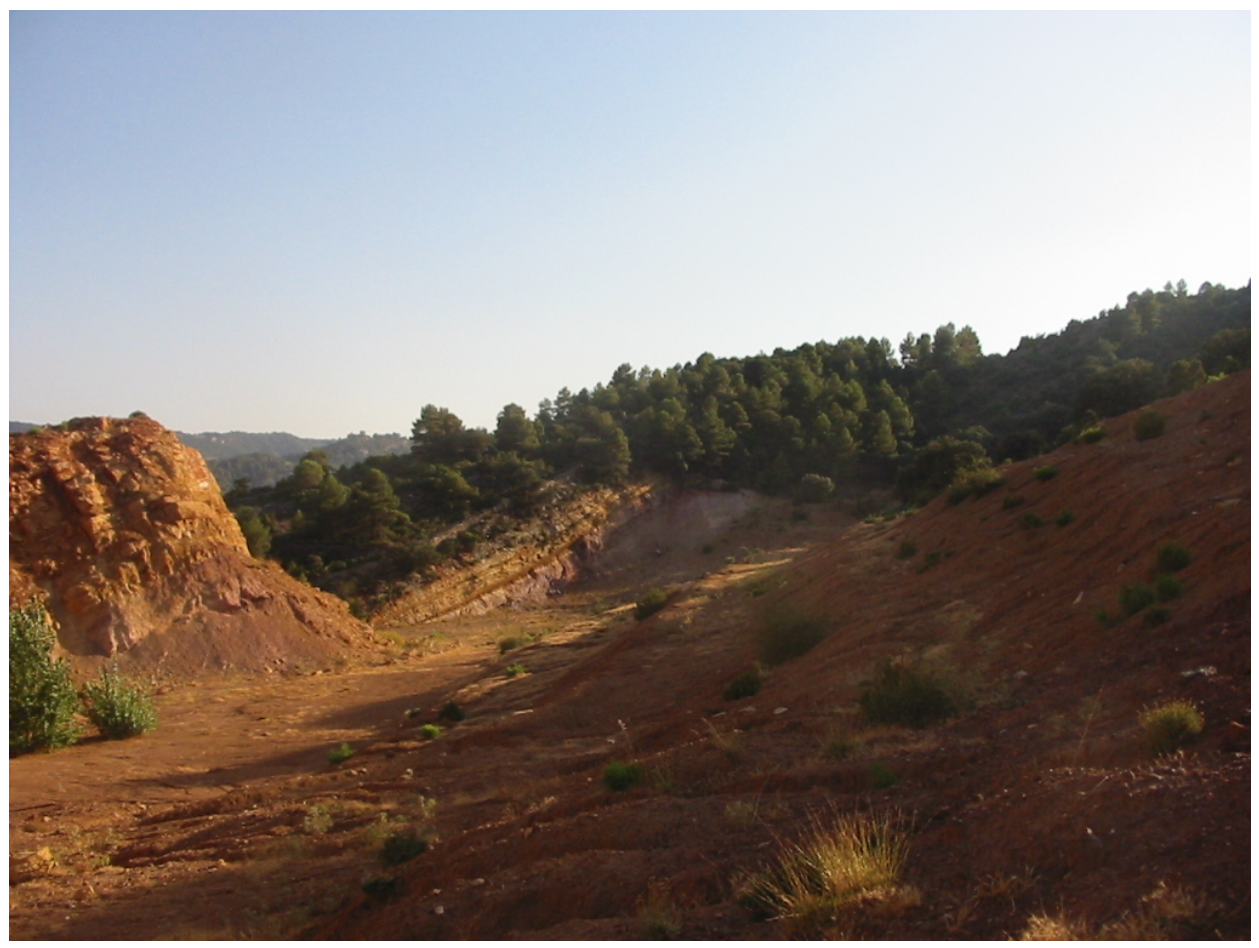

FOTOGRAFIA 1. PARADA 1

Restes de les antigues explotacions argiloses de la Mina Dolores. Beseit

\section{PARADA 2. EMBASSAMENT DE LA PENA, (pertany al terme municipal de Vall-de-roures, comarca del Matarranya). (Full 521).}

Després de fer la parada anterior cal arribar a Beseit, per tal d'agafar el camí que surt del poble per la dreta. Aquest camí es dirigeix cap a l'Embassament de la Pena. En aquest lloc farem la present aturada, després d'haver recorregut uns $8 \mathrm{Km}$, des de la parada anterior.

En aquest recorregut fins a Beseit hem tornat a trobar els materials esmentats a la parada anterior. Després, des del poble fins a l'embassament hem trobat afloraments dels materials detrítics de la Formació Montsant; tot i així, a la base de l'embassament hem trobat els afloraments dels materials mesozoics (del Juràssic i del Cretàcic). Tots quests materials formen part de la làmina d'encavalcament de la Pena, la qual es troba encavalcant als materials cenozoics de la Depressió Geològica de l’Ebre, situada al Nord dels anteriors.

Més endavant, baixant de l'embassament cap a la població de Vall-de-roures es torna a veure com aquests materials encavalquen als oligocens de la Depressió Geològica de l'Ebre. Entre aquests materials discorre encaixonat el riu de la Pena. FOTOGRAFIA 2. 


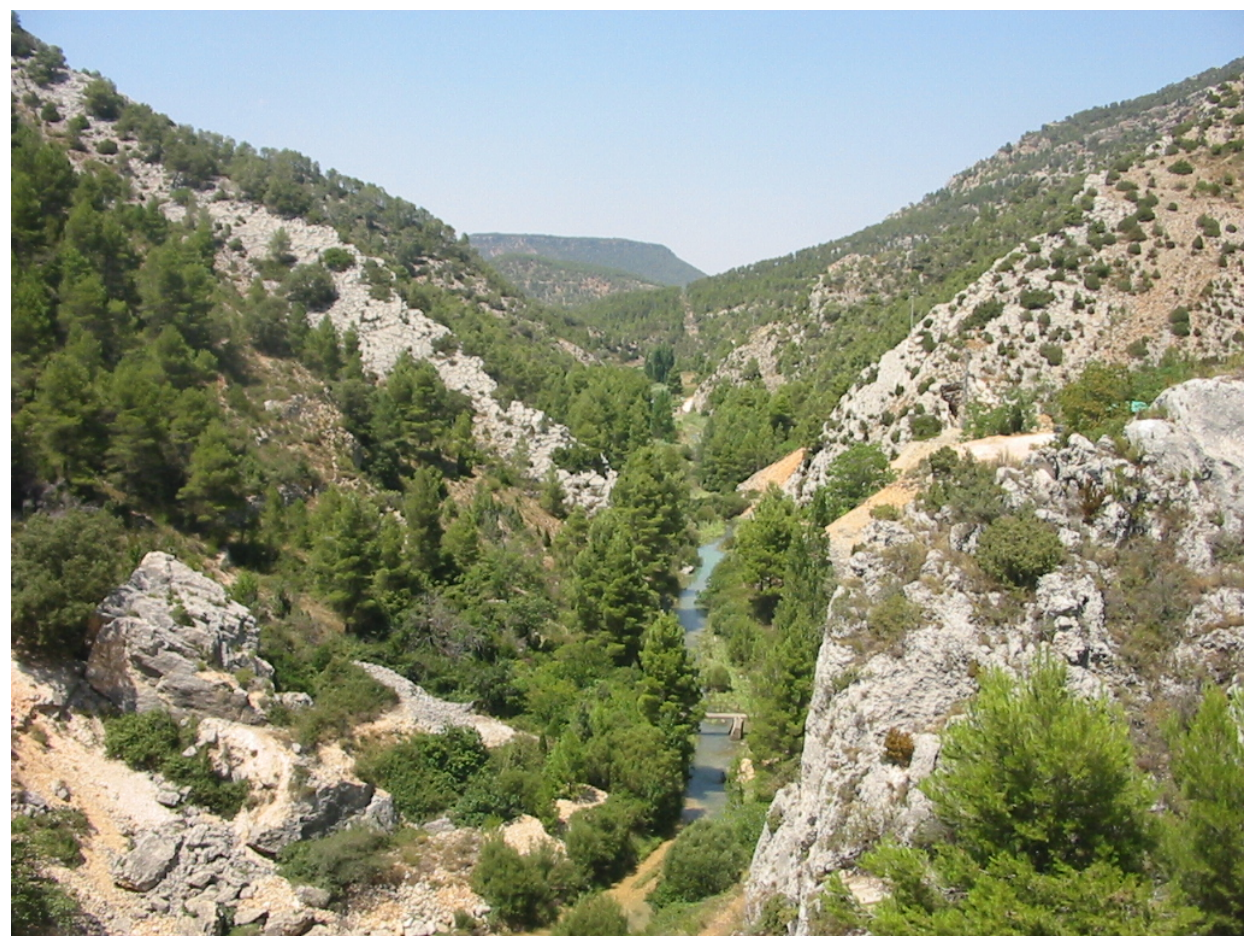

FOTOGRAFIA 2 (PARADA 2)

El riu Pena des de la presa de l'embassament

Per d'altra banda, en arribar a la presa, haurem trobat les antigues instal-lacions mineres, dedicades a l'extracció i al tractament d'àrids, per tal d'ésser emprats per la construcció de la presa. Les explotacions es troben molt a prop, i van ésser utilitzats els materials carbonats mesozoics dels que hem parlat anteriorment, de la làmina d'encavalcament de la Pena., per on estem ara situats, a la presa de l'embassament.

Pel que respecta a les instal-lacions mineres, a les tremuges i als plans inclinats, cal dir que quests elements formen part del patrimoni miner de la comarca del Matarranya, i també del conjunt de la Comunitat d’Aragó. FOTOGRAFIA 3 


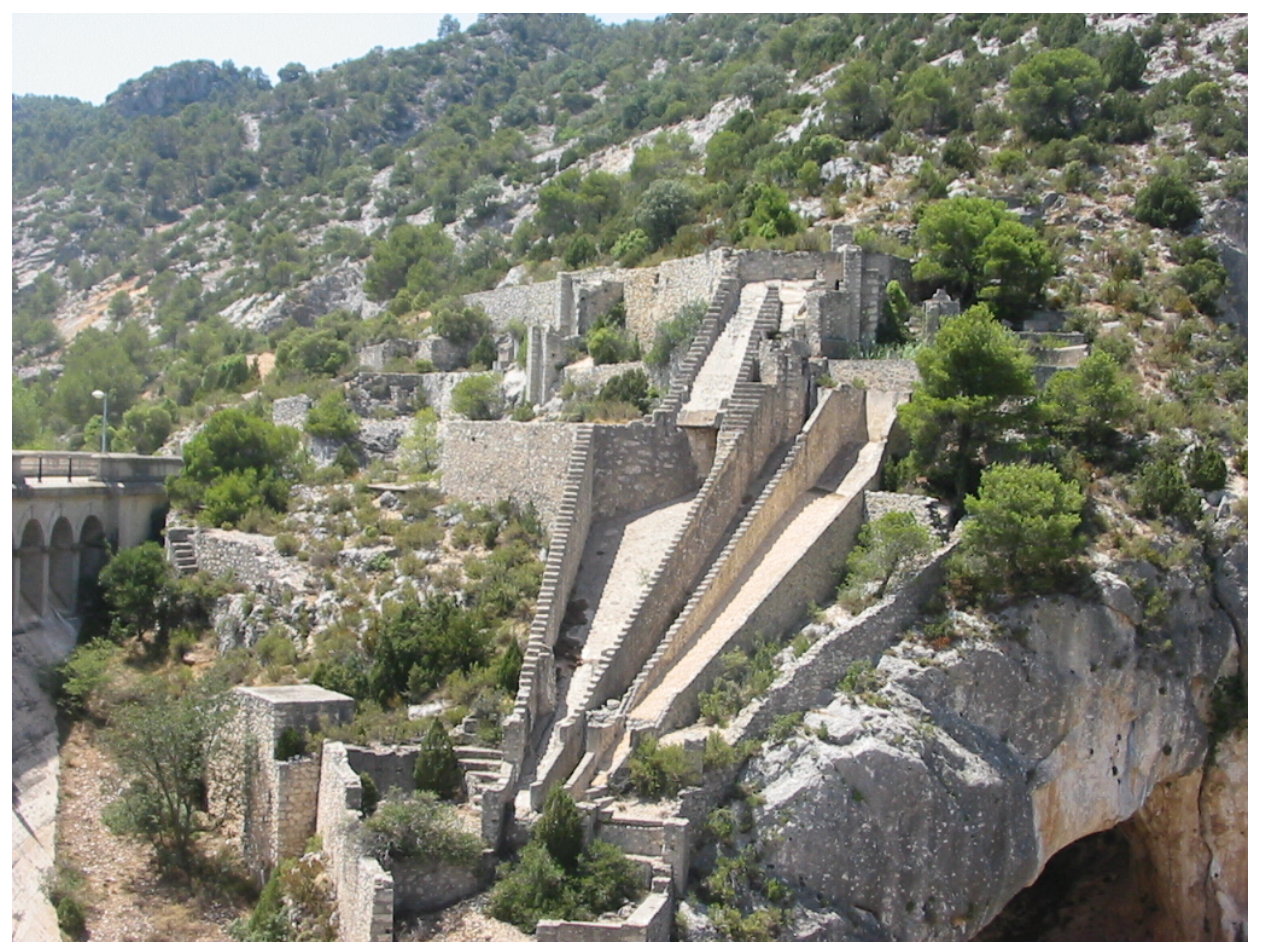

FOTOGRAFIA 2 (PARADA 2)

Planta de tractament d'àrids, a la presa de l'embassament de la Pena

PARADA 3. CARRETERA A VALL-DE-ROURES, (terme municipal de Vall - de - Roures, comarca del Matarranya). (Full 521).

Des de la parada anterior, cal continuar cap a la propera població de Vall-deroures. Abans d'arribar a la cruilla amb la carretera A-1221 (la qual condueix cap a Fondespatlla), farem una nova aturada, a uns 2’ $5 \mathrm{Km}$ de l'anterior. Així, aquesta aturada la podríem efectuar a la vall del riu la Pena.

En aquest recorregut, haurem anat travessant els afloraments dels materials carbonats mesozoics, els quals formen part de la làmina d'Encavalcament de la Pena. Més endavant, poc abans d'arribar a l'indret de l'aturada, veurem com aquests materials encavalquen als afloraments cenozoics de la Depressió Geològica de l'Ebre, per on estem ara situats.

Així, des d'on som ara, es veu clarament el front d'encavalcament, apareixent els materials mesozoics dibuixant el flanc septentrional d'un plec (que més avall encavalca als terrenys cenozoics). FOTOGRAFIA 3 (a la pàgina següent).

PARADA 4 - CONDICIONAL. CASTELL DE VALL - DE - ROURE, (terme municipal de Vall - de - Roures, comarca del Matarranya). (Full 521). 
Des de la parada anterior, cal continuar definitivament cap a la propera població de Vall-de-roures. En arribar-hi, ens caldrà anar cap el Castell, per on farem la darrera aturada, a uns $4 \mathrm{Km}$ de l'anterior.

En aquest recorregut, haurem anat travessant els afloraments dels materials cenozoics, eminentment detrítics, els quals formen part de la Depressió Geològica de l'Ebre, per on estem ara situats. Aquests materials pertanyen al Complex Al-luvial de Gandesa - Horta de Sant Joan

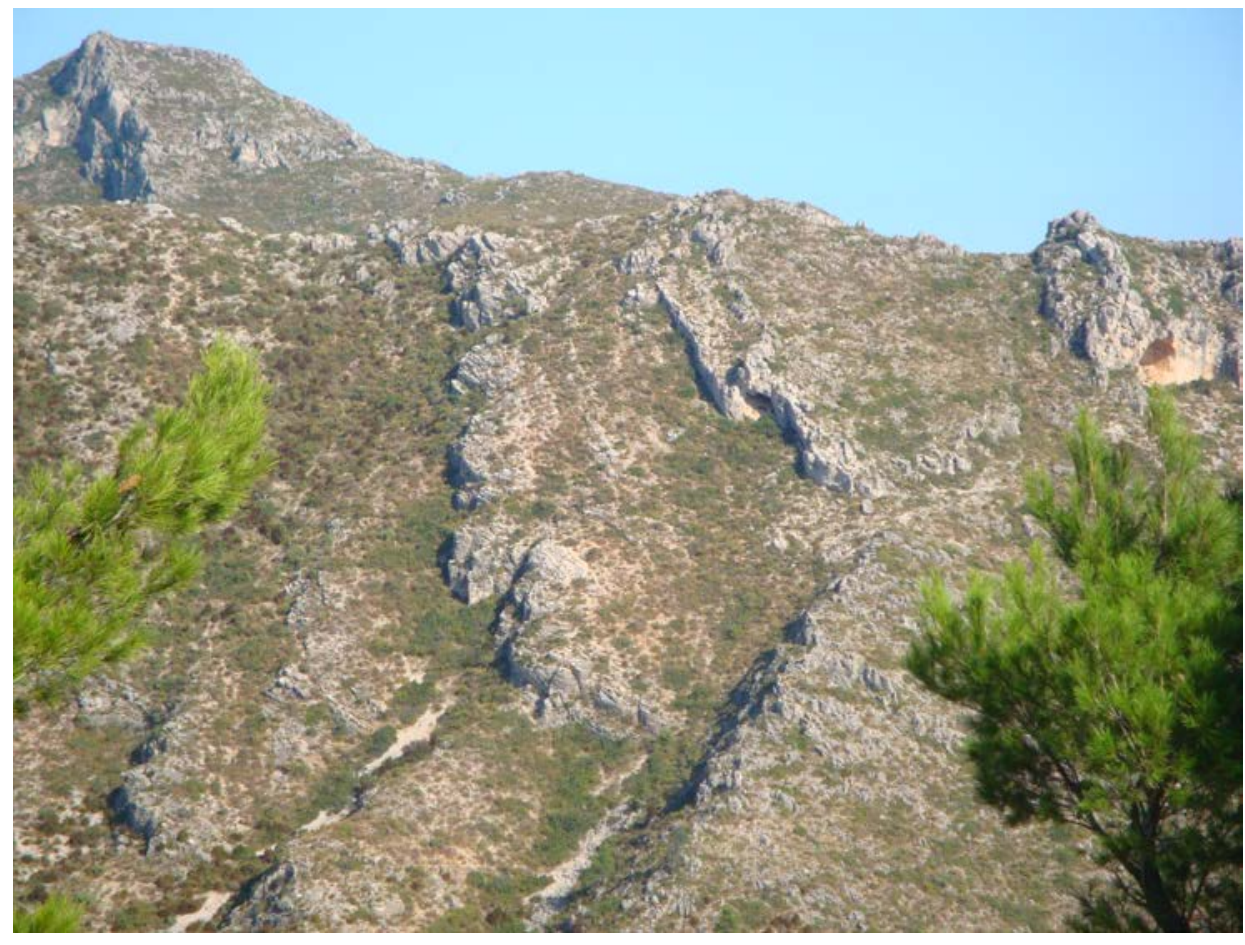

FOTOGRAFIA 3. PARADA 3

Un aspecte del front d'encavallcament de lamina de la Pena. Beseit

\section{EN AQUEST INDRET FINALITZA EL RECORREGUT}

\section{REFERÈNCIES BIBLIOGRÀFIQUES}

GUIMERÀ, J. et altri (1992).- Geologia (II), Història Natural dels Països Catalans, Vol.2, 547 pag. Enciclopèdia Catalana, S.A. Barcelona 
IGME (1974).- Mapa Geológico de España a escala 1:200.000. Sintesis de la Cartografia existente. Hoja y memória nº 41 (Tortosa). Inst. Geol. Min. España. Minist. Indústria. Madrid

MATA-PERELLÓ, J.M. (1989).- Una recerca mineralògica per les terres de l’Ebre: del Matarranya al Priorat. But. Col. Ofi, de Doctors i Llicenciats, nº 67, 15pag. Barcelona

MATA-PERELLÓ, J.M. (1991).- Els Minerals de Catalunya. Arxius de la Secció de Ciències, t. XCIII, 442 pag. Institut d'Estudis Catalans. Barcelona

MATA-PERELLÓ, J.M. (1995a).- Inventari Mineralògic de la comarca de la Ribera d’Ebre, Terra Endins, n 9 , 23 pag. Manresa

MATA-PERELLÓ, J.M. (1995b).- Inventari Mineralògic de la comarca de la Terra Alta, Terra Endins, $\mathrm{n}^{\circ} 10,22$ pag. Manresa

MATA-PERELLÓ, J.M. (1996).- Itinerari geològic i mineralògic entre Gandesa, la Fontcalda i Vall-de -roures. Inèdit., 12 pàgines. Manresa

MATA-PERELLÓ. J.M. (1997).- Recerca geològica i mineralògica per les comarques de la Terra Alta i del Matarranya: des de Gandesa a Bot i Horta de Sant Joan, i des de Vallde-roures a Fondespatlla. Inèdit, 17 pàg. Manresa

MATA-PERELLÓ. J.M. (2000a).- Recerca geològica i mineralògica per les comarques de la Terra Alta i de la Ribera de l'Ebre: des de Pinell de Brai i Prat de Compte a Gandesa i a Mora d’Ebre. Algeps, sèrie B, nº 171, 14 pàg. Manresa

MATA-PERELLÓ. J.M. (2000b).- Recerca geològica i mineralògica per les comarques de la Terra Alta i del Matarranya: des de Gandesa a Vall-de-roures i a Fondespatlla. Algeps, sèrie $B, n^{\circ} 176,18$ pàg. Manresa

MATA-PERELLÓ. J.M. (2001a).- Recorregut de recerca geològica i mineralògica per les comarques de la Ribera d'Ebre i de la Terra Alta: des d'Ascó a Pinell de Brai, i des de Prat de Compte a Horta de Sant Joan, Inèdit, 18 pàg. Manresa

MATA-PERELLÓ. J.M. (2001b).- Recorregut de recerca geològica i mineralògica per les comarques de la Terra Alta i del Matarranya: des d'Horta de Sant Joan a Vall-de-roures i a Fontespatlla Inèdit, 18 pàg. Manresa

MATA-PERELLÓ. J.M. (2005a).- Recorreguts per la comarca de la Terra Alta: des de Pinell de Brai a Prat de Compte i a Horta de Sant Joan. Inèdit. 12 pàgines. Manresa

MATA-PERELLÓ. J.M. (2005b).- Recorreguts de recerca geològica i mineralògica per les comarques de la Terra Alta i del Matarranya: des d'Arnes a Vall-de-roures i Beseit. Inèdit. 10 pàgines. Manresa 
MATA-PERELLÓ. J.M. (2011).- Recorregut de recerca geològica i mineralògica per la comarca del la Matarranya: des de Beseit a Fondespatla. Inèdit. 10 pàgines. Manresa

RIBA, O. et altri (1976).- Geografia Física dels Països Catalans, Edit. Ketres, 254 pàgines. Barcelona. 
RODENO. Revista de geología aragonesa 